\title{
Preparation of Polyurethane Adhesive from Wood Sawdust polyol: Application of Response Surface Methodology for Optimization of Catalyst and Glycerol
}

\author{
Soheyla Daneshvar ${ }^{1 \mathbb{D}}$, Rabi Behrooz ${ }^{1, *} \mathbb{( \mathbb { D }}$, Saeed Kazemi Najafi ${ }^{1 \mathbb{D}}$, Gity Mir Mohamad Sadeghi ${ }^{2} \mathbb{D}$ \\ 1 Department of Wood and Paper Science and Technology, Faculty of Natural Resources, Tarbiat Modares University, Noor, \\ Iran; soheyladaneshvar@ rocketmail.com (S.D.); rabi.behrooz@ modares.ac.ir (R.B.); skazemi@ modares.ac.ir (S.K.N.); \\ 2 Department of Polymer Engineering and Color Technology, Amirkabir University of Technology, Tehran, Iran; \\ gsadeghi@aut.ac.ir (G.M.M.S.); \\ * Correspondence: rabi.behrooz@modares.ac.ir (R.B.);
}

Scopus Author ID 37460907300

Received: 28.03.2021; Revised: 5.05.2021; Accepted: 8.05.2021; Published: 10.06.2021

\begin{abstract}
Response surface methodology (RSM) was applied to optimize catalyst and glycerol values as suitable additives in polyurethane adhesive production and determine the appropriate gel time. Polyurethane adhesive was prepared using polyol, two types of diisocyanate (PMDI and TDI), catalyst, and glycerol with equal $\mathrm{NCO} / \mathrm{OH}$ ratio. Polyol was produced using the liquefaction process of Beechwood sawdust with ethylene carbonate solvent at $130^{\circ} \mathrm{C}$ for 120 minutes under atmospheric pressure. Fourier transform infrared spectroscopy (FTIR) results revealed the existence of the hydroxyl groups in the liquefied wood and confirmed that the liquefied wood sawdust is a source of polyols and a potential chemical stock for the synthesis of polyurethane. Also, the adhesive bonding strength was evaluated by lap shear strength. The result of optimization by response surface methodology showed that catalyst and glycerol values were $0.11 \%$ and $1.56 \%$ for PU adhesive with PMDI, and catalyst and glycerol values of $0.34 \%$ and $3.12 \%$ for PU adhesive with TDI were appropriate.
\end{abstract}

Keywords: liquefaction; polyurethane adhesives; glycerol, catalyst; response surface methodology.

(C) 2021 by the authors. This article is an open-access article distributed under the terms and conditions of the Creative Commons Attribution (CC BY) license (https://creativecommons.org/licenses/by/4.0/).

\section{Introduction}

Polyurethane is one of the most significant and diverse polymeric materials that Otto Bayer discovered in 1973. Polyurethane exists in various forms such as foams [1,2], films, elastomers, and adhesives. Industrial polyurethane is a petroleum-based polymer that is produced by polyols and isocyanate. In recent years, due to reduce fossil sources and the increase of the world's population at the rate of $1 \%$ per year [3] and environmental concerns, renewable sources such as agricultural wastes [4-8] and wood wastes had been used for the production of biopolyol [9-11].

Agricultural [12-14] and forestry [15] residues as lignocellulosic material are generally composed of cellulose, hemicellulose, and lignin, mainly consisting of two or more hydroxyl groups per molecule. The hydroxyl groups function for reaction in many chemical modifications and production of many polymers as polyurethane, etc. $[16,17,18]$.

The liquefaction process is [19-21] used for conversion of lignocellulosic to polyol [2224]. This process is carried out in the presence of solvents and catalysts at a high temperature and atmospheric pressure [25]. Polyols containing hydroxyl groups are a major component in 
the preparation of polyurethane adhesives [26-28]. Usually, lignocellulosic liquefaction is carried out with different polyhydric alcohols [14,29] as solvents [30-32]. The main problem of polyhydric alcohols is low-speed liquefaction and the need for high temperatures. The rate of liquefaction of cellulose and hardwood with cyclic carbonates such as ethylene carbonate (EC) and propylene carbonate (PC) due to their high permittivity value was faster than polyhydric alcohols. It is known that, for an acid-catalyzed reaction in no aqueous solvents, the influence of acid depends on the permittivity of the solvent [33]. Due to a high liquefaction speed and the need for a low temperature,the liquefaction process with ethylene carbonates is affordable than polyhydric alcohols. The polyol produced from lignocellulosic resources used in the preparation of polyurethane adhesives.

Polyurethane adhesives are one of the most important and significant polymeric materials used in industry. Polyurethane adhesives are of high strength against chemicals, moisture, and temperature[34]. Also, due to low toxicity or low dangers to human health, the polyurethane adhesives are more notes worthy than other adhesives such as phenol and ureaformaldehyde[26,35]. Because PF and UFadhesives have no resistance against hydrolysis, they also have formaldehyde emission, which is dangerous gas for human health [36,37]. The properties of polyurethane adhesive (chemical, mechanical and physical) are determined based on its formulations[38]. Lately, in the production of polyurethane adhesive using isocyanate and polyol, effective additives such as catalysts and glycerol as cross-linker have been used to increase the adhesive strength[39,40].

In industrial production, usually, isocyanates containing $\mathrm{NCO}$ groups used in polyurethane adhesives production are 2,4 and 2,6 toluene diisocyanate (TDI) and poly 4,4 diphenylmethane diisocyanate (PMDI). The $\mathrm{NCO} / \mathrm{OH}$ ratio in adhesive formulation the most effects on adhesive strength characteristic[41]. Whatever, the $\mathrm{NCO} / \mathrm{OH}$ ratio is higher than 1 in the polyurethane adhesives, the adhesive bond strength increases due to perfect reaction between polyol and isocyanate and formation of urethane bond.The adhesive bond strength is evaluated by using lap shear strength $[39,40]$.

The common catalyst used to polyurethane adhesives production is Dibutyltin dilaurate (DBTL). Catalysts are used as reaction accelerators and gel time reducers in the consumable adhesives. Glycerol is a simple polyol compound that has three hydroxyl groups that are responsible for reaction with isocyanate and increased adhesives bonding strength[39,40,42].

Response surface methodology(RSM) is a beneficial statistical method. This technique is used to for analysis the effects of several independent variables on the response. RSM has a significant program in optimization and the process design and also the amelioration of existing design $[43,44]$. This method is more practical than the experimental method because the experimental method involves interactive effects among the variables and shows the overall effects of the parameters on the process [45,46]. So far, this methodology has not been used for optimization adhesive additives and determination of appropriate gel time. The gel time is a very important characteristic in adhesives because this time determines the usability of adhesive. Low gel time means fast curing and low working time in adhesive. With response surface methodology can be determined appropriate time. This study aims to prepare polyurethane adhesive based on lignocellulosic waste sawdust and optimization suitable additives by using RSM. 


\section{Materials and Methods}

\subsection{Materials}

Beech wood sawdust with 60 mesh particle size as lignocellulosic raw material for the liquefaction process was used. The sawdust oven-dried at $105^{\circ} \mathrm{C}$ overnight before use. Ethylene carbonate as a solvent and sulfuric acid as catalysts in the liquefaction process was purchased from (Merck, German). The PMDI and TDI were used as isocyanate compounds. For the polyurethane adhesive preparation, glycerol and dibutyltin dilaurate were purchased from Merck Company. The wood of Beech (Fagus orientalis) was used for the lap shear test [39].

\subsection{Liquefaction process.}

The experimental method adopted was as described by Xie and Chen, 2005:Liquefying reagent $32.5 \mathrm{~g}$ as a solvent and $0.97 \mathrm{~g}$ catalyst (3 wt\% for the liquefying reagent) were added to a three-neck flask $(250 \mathrm{ml})$ which was equipped with a stirrer, thermometer, and reflux condenser then the flask was immersed in a silicon oil bath that had been preheated, and after that, the temperature was reached to the desired level, 6.5g Beech sawdust was added into the flask. The mixture to obtain homogeneously liquefied product during the liquefaction process was continuously stirred. For all experiments, liquefaction was conducted at high temperatures level $130^{\circ} \mathrm{C}$ and retention time 120 min under ambient pressure. At the end of set time, the flask was immersed in cold water to quench the reaction [39].

\subsection{Evaluation of residue content and liquefaction yield.}

The liquefied product was diluted by a universal diluent, 1, 4-dioxane, in excess of $80 \%$. After that, the residue was separated with a glass filter and rinsed thoroughly with the dioxane, and oven-dried at $105^{\circ} \mathrm{C}$ for $24 \mathrm{~h}$. The residue content and yield percent were calculated by equations (1) and (2).

Residue $(\%)=($ Mass of residue/Mass of starting sawdust $) \times 100$

Yield $=(1-$ residue $)(\%)$

\subsection{Determination of the acid number and hydroxyl number of biopolyols.}

The acid number was determined per ASTM D4662-08. First, $2 \mathrm{~g}$ of biopolyols in 50 $\mathrm{ml}$ of ethanol were dissolved. Then titration was performed using a $0.1 \mathrm{~N} \mathrm{NaOH}$ standard solution. The acid number Was calculated using equation (3).

$$
\text { Acid Number }(\mathrm{mg} \mathrm{KOH} / \mathrm{g})=(\mathrm{C}-\mathrm{B}) \times \mathrm{N} \times 56.1 / \mathrm{W}
$$

In this equation $C$ is the volume of $\mathrm{NaOH}$ standard solution, $\mathrm{ml} ; B$ is the volume of blank solution, $\mathrm{ml} ; W$ is sample weight, $\mathrm{g}$ and $N$ is the equivalent concentration of $\mathrm{NaOH}$ standard solution, $\mathrm{mol} / \mathrm{L}$.

The hydroxyl number was determined per ASTM D4274-05D. 1g of biopolyol was added into a $150 \mathrm{ml}$ beaker, and then biopolyol was dissolved with $10 \mathrm{ml}$ of esterification reagent $(150 \mathrm{~g}$ phthalic anhydride, $900 \mathrm{ml}$ of dioxane and $100 \mathrm{ml}$ pyridine). Then, the beaker with aluminum foil was covered and for 30 minutes put into a boiling water bath at $100^{\circ} \mathrm{C}$. After the heating period, the beaker was cooled at room temperature, then $5 \mathrm{ml}$ of distilled 
water and $20 \mathrm{ml}$ of dioxane/water solution $(4 / 1, V / V)$ were added to the beaker, and the beaker soluble was titrated with $1 \mathrm{~mol} / \mathrm{L} \mathrm{NaOH}$. The hydroxyl number was calculated using equation (4).

Hydroxyl Number $(\mathrm{mg} \mathrm{KOH} / \mathrm{g})=((\mathrm{B}-\mathrm{S}) \times \mathrm{N} \times 56.1 / \mathrm{W})+$ acid Number

In this equation $S$ is the volume of $\mathrm{NaOH}$ standard solution, $\mathrm{ml} ; B$ is the volume of blank solution, $\mathrm{ml} ; W$ is sample weight, $\mathrm{g} ; \mathrm{N}$ is the equivalent concentration of $\mathrm{NaOH}$ standard solution, $\mathrm{mol} / \mathrm{L}$.

\subsection{FT-IR analysis.}

FTIR spectroscopic analysis was performed using an AVATAR model instrument (Thermo Electron Corporation, USA). Spectral data were collected "between"400-4,000 cm-1 averaging 40 scans at a resolution of $4 \mathrm{~cm}^{-1}$. Transmittance measurements using the $\mathrm{KBr}$ pellet method were conducted [39].

\subsection{Preparation of $P U$ adhesives.}

The polyol, glycerol as cross-linker $(1,2,3,4,5 \%)$ and Dibutyltin dilaurate (DBTL) as catalyst $(0.1,0.2,0.3,0.4,0.5 \%)$ were mixed together and stirred at $400 \mathrm{rpm}$ with a stirrer for approximately $3 \mathrm{~min}$ at room temperature. Then isocyanate adducts were added to the mixture, and adhesive preparation continues at the same speed for $3 \mathrm{~min}$. The polyurethane wood adhesive using a brush was applied onto wood surfaces and then attached sample cured at room temperature for $24 \mathrm{~h}$. The polyurethane adhesives were prepared by using two diisocyanates, such as polymeric $4,4^{\prime}$-methylene diphenyl diisocyanate (PMDI) and toluene diisocyanate TDI. The polyurethane adhesives were prepared by equal NCO/OH [39]. Optimization of catalyst and glycerol quantity added to polyurethane adhesive to determine gel time was carried out using DESIGN EXPERT 7(Stat-Ease Inc., Minneapolis, USA) software.

\subsection{Woodspecimens preparation.}

According to ASTM D906-98, the beechwood pieces were converted into strips to size $25 \times 300 \times 3 \mathrm{~mm}^{3}$ and then polished by sandpaper before application [39].

\subsection{Lap shear strength test.}

Lap shear strength tests were carried out according to the ASTM D906-98. The adhesive onto the surface of the wood in the bonding section of $30 \times 25 \mathrm{~mm}$ was applied. The application rate adhesive onto the wood surface in the bonding area was $0.2 \mathrm{mg} / \mathrm{mm}^{2}$. Then two surfaces of wood were placed together under the pressure of $2.5 \mathrm{~kg}$ at room temperature for $24 \mathrm{~h}$. After that, samples were kept at a temperature $25^{\circ} \mathrm{C}$ and relative humidity of $50 \% \pm$ $5 \%$ for one week. The wood sample was tested for lap shear strength using a SANTAM model STM-20 and was pulled at a rate of $5 \mathrm{~mm} / \mathrm{min}$ [39].

\subsection{Determination of gel time.}

Gel time is the maximum time during that the system for use remains in a fluid state. The fluidity of polyurethane adhesive was investigated manually using a glass rod at room temperature [26,39]. 


\subsection{Response surface methodology.}

RSM is a useful statistical technique for the optimization of multiple variables. The DESIGN EXPERT software was used for statistical analysis of the obtained data [47]. In this study, the response surface and optimization were carried out by studying the effect of two variables, including glycerol and catalyst with 3 repeats, a five-level. A design of 29 experiments was formulated for eight factorial designs with 3 replicates and five replicates at the central points for both polyurethane adhesives PMDI and TDI. The employed model for the polyurethane adhesive PMDI was the 2F1model (Eq.5) and the second-order polynomial model (Eq.6) for the polyurethane adhesive TDI.

$$
\begin{aligned}
& y=\beta o+\sum_{i=1}^{k} \beta i X i+\sum \sum \beta i j X i X j \\
& y=\beta o+\sum_{i=1}^{k} \beta i X i+\sum_{i=1}^{k} \beta i i x i^{2}+\sum \sum \beta i j X i X j+\varepsilon
\end{aligned}
$$

where $\mathrm{Y}$ is the predicted response (gel time), $\mathrm{X}_{\mathrm{i}}$ is the input variables, $\mathrm{X}_{\mathrm{i}}^{2}$ is the square effect, $\mathrm{X}_{\mathrm{i}} X_{\mathrm{j}}$ is the interaction effect, $\beta_{0}$ is the intercept term, $\beta_{\mathrm{i}}$ is the linear effect, $\beta_{\mathrm{ii}}$ is the squared effect, $\beta_{\mathrm{ij}}$ is the interaction effect, $k$ is variables number and $\varepsilon$ is a random error.

The optimum amounts of the chosen variables were acquired by dissolving the regression equation at desired amounts of the process responses as the optimization criteria. Two independent variables and five levels for 29 the experiments (PU PMDI and PU TDI) in the central composite design (CCD) study are shown in Table $1[43,48]$.

Table1.Levels of the independent variables (PU PMDI and TDI).

\begin{tabular}{l|c|c|c|c|c} 
Independent variables & \multicolumn{6}{c}{ Range and level } \\
\hline & $\boldsymbol{- \alpha}$ & $\mathbf{- 1}$ & $\mathbf{0}$ & $\boldsymbol{+ 1}$ & $\boldsymbol{+ \alpha}$ \\
\hline A-Catalyst (\%) & 0.1 & 0.2 & 0.3 & 0.4 & 0.5 \\
\hline B-Glycerol (\%) & 1 & 2 & 3 & 4 & 5
\end{tabular}

\section{Results and Discussion}

\subsection{Polyol characteristics.}

The liquefaction process was carried out by using ethylene carbonate solvent. EC, due to high permittivity is causes degradation of macromolecules of sawdust and converting them into soluble components [33]. Table 2 shows the properties of polyol in $130^{\circ} \mathrm{C}$ and $120 \mathrm{~min}$. Liquefaction process amorphous structure of lignocellulosic material due to easily accessible to solvent occurs rapidly, but crystalline structure due to less accessible to solvent occurs slower and needs more time for the reaction $[39,49]$.

Table 2. Properties of polyol $\left(130^{\circ} \mathrm{C}, 120 \mathrm{~min}\right)$.

\begin{tabular}{l|c|c|c|c}
$\begin{array}{l}\text { Beech wood } \\
\text { Sawdust }\end{array}$ & $\begin{array}{c}\text { Acid number(mg } \\
\text { KOH/g) }\end{array}$ & $\begin{array}{c}\text { Hydroxyl } \\
\text { number(mg KOH/g) }\end{array}$ & Yield (\%) & $\begin{array}{c}\text { Residue } \\
\text { content (\%) }\end{array}$ \\
\hline Polyol & 12.9 & 209.25 & 85 & 15
\end{tabular}

\subsubsection{The spectrum of the after and before liquefaction.}

The IR spectrum of wood sawdust (before liquefaction) and polyol (after liquefaction)are shown in Figure 1. For the sawdust, there are strong broad $\mathrm{OH}$ stretching 3411 $\mathrm{cm}^{-1}$ and C-H stretching in methyl and methylene groups $\left(2854-2926 \mathrm{~cm}^{-1}\right)[39,50]$. The peak $1738 \mathrm{~cm}^{-1}$ belong to $\mathrm{C}=\mathrm{O}$ stretching in acetyl groups of hemicelluloses (xylan/glucomannan), 
and $1427 \mathrm{~cm}^{-1}$ belong to aromatic skeletal vibration combined with $\mathrm{CH} 2$ symmetrical bending mode of hydroxymethyl in crystalline cellulose [51,52] and -C-O- stretching band at $1248 \mathrm{~cm}^{-}$ 1 confirmed the formation of ester bonds [39,50]. Also, the wide spread peak $3340 \mathrm{~cm}^{-1}$ corresponds to the $-\mathrm{OH}$ stretching vibration. The peak $2869 \mathrm{~cm}^{-1}$ corresponded to a $\mathrm{CH}$ stretching vibration. A strong band at $1720 \mathrm{~cm}^{-1}$ corresponding to carbonyl groups was observed in addition to these aromatic bands $[33,52]$. The peak $1450 \mathrm{~cm}^{-1}$ corresponded to a $\mathrm{C}=\mathrm{C}$ stretching caused by aromatic structure[53].

The peaks of $3300-3500 \mathrm{~cm}^{-1}$ in both samples were belonging to $\mathrm{OH}$ groups. The hydroxyl groups are the important sites for reaction in many chemical modifications and many polymers such as polyurethane [39]. According to Figure 1, it clearly can be seen that the peak of $1427 \mathrm{~cm}^{-1}$ corresponding to wood sawdust has decreased in the liquefied sample (polyol). The liquefaction process has the ability to convert wood sawdust into soluble substances. Wood sawdust components during the liquefaction process could be converted into small components with many active hydroxyl groups appropriate for chemical reaction. This polyol (liquefied products) could be used in the production of polyurethane [49]. Because of having a high xylan content, Beech wood sawdust (heartwood) showed a stronger carbonyl band at $1738 \mathrm{~cm}^{-1}$. This wavenumber for liquefied sample (polyol) being shifted to a lower value $\left(1720 \mathrm{~cm}^{-1}\right)[52,53]$. The appearance of the band $1604 \mathrm{~cm}^{-1}$ in the liquefied sample (polyol) and $1645 \mathrm{~cm}^{-1}$ in wood sawdust shows the existence of a large number of methoxyl groups in heartwood[39].

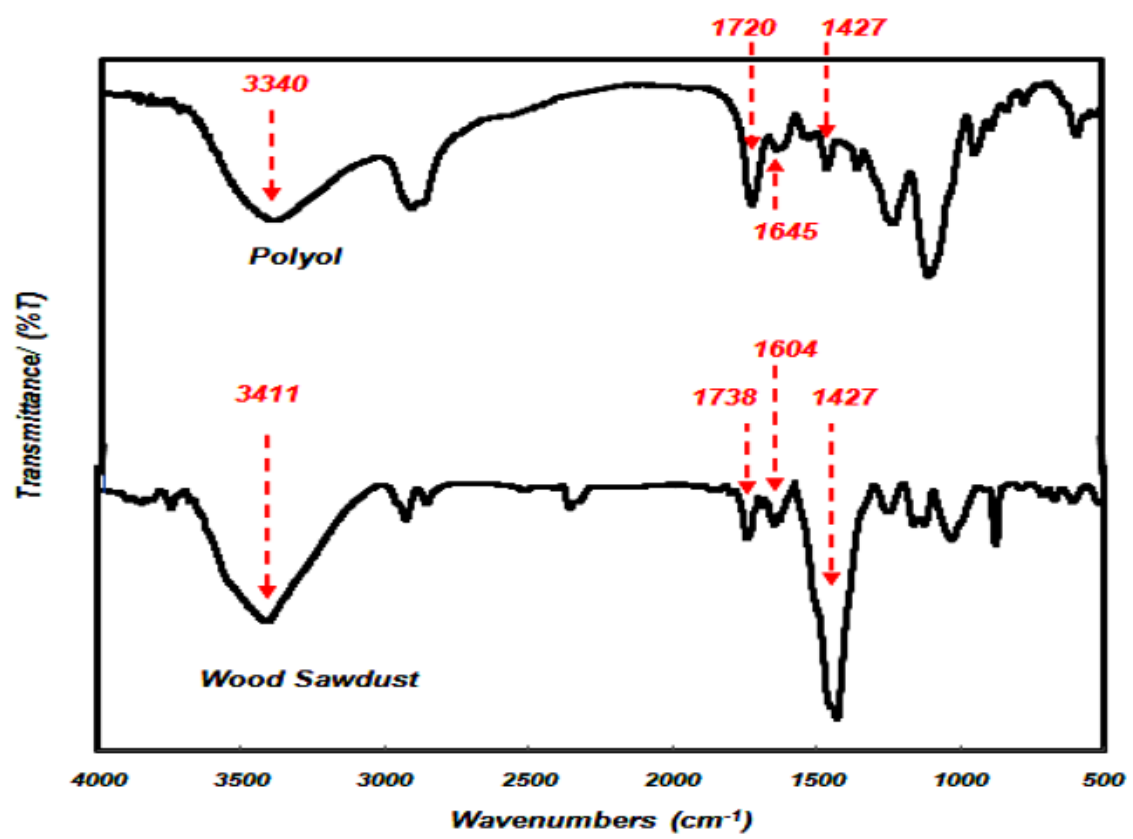

Figure 1. FTIR spectra of before liquefaction (sawdust) and after liquefaction (polyol).

3.2.Optimization of catalyst and glycerol values for determination of gel time.

3.2.1. Polyurethane adhesive with PMDI.

The real value and the coded value obtained from the experimental design shown in Table 3. The results observed value and predicted value of the gel time are shown in Table 4. Also, Table 4 can be seen the results of gel time and lap shear strength after adding catalyst and glycerol to the adhesive compound. 
Table 3. Real value and a coded value obtained from (CCD) experimental design (PU PMDI).

\begin{tabular}{c|c|c|c|c|c|c|c|c|c} 
Run & \multicolumn{2}{|c|}{ Glycerol $(\boldsymbol{\%})$} & \multicolumn{2}{c}{ Catalyst $(\boldsymbol{\%})$} & Run & \multicolumn{2}{c|}{ Glycerol (\%) } & \multicolumn{2}{c}{ Catalyst (\%) } \\
\hline 1 & 5 & $(1)^{*}$ & 0.1 & $(-1)^{*}$ & 16 & 3 & $(0)^{*}$ & 0.3 & $(0)^{*}$ \\
\hline 2 & 3 & $(0)$ & 0.1 & $(-1)$ & 17 & 5 & $(1)$ & 0.3 & $(0)$ \\
\hline 3 & 1 & $(-1)$ & 0.5 & $(1)$ & 18 & 1 & $(-1)$ & 0.3 & $(0)$ \\
\hline 4 & 1 & $(-1)$ & 0.1 & $(-1)$ & 19 & 5 & $(1)$ & 0.5 & $(1)$ \\
\hline 5 & 3 & $(0)$ & 0.3 & $(0)$ & 20 & 3 & $(0)$ & 0.3 & $(0)$ \\
\hline 6 & 5 & $(1)$ & 0.1 & $(-1)$ & 21 & 5 & $(1)$ & 0.3 & $(0)$ \\
\hline 7 & 1 & $(-1)$ & 0.1 & $(-1)$ & 22 & 3 & $(0)$ & 0.3 & $(0)$ \\
\hline 8 & 1 & $(-1)$ & 0.3 & $(0)$ & 23 & 3 & $(0)$ & 0.5 & $(1)$ \\
\hline 9 & 5 & $(1)$ & 0.5 & $(1)$ & 24 & 3 & $(0)$ & 0.1 & $(-1)$ \\
\hline 10 & 1 & $(-1)$ & 0.1 & $(-1)$ & 25 & 3 & $(0)$ & 0.3 & $(0)$ \\
\hline 11 & 5 & $(1)$ & 0.1 & $(-1)$ & 26 & 5 & $(1)$ & 0.3 & $(0)$ \\
\hline 12 & 3 & $(0)$ & 0.5 & $(1)$ & 27 & 1 & $(-1)$ & 0.5 & $(1)$ \\
\hline 13 & 5 & $(1)$ & 0.5 & $(1)$ & 28 & 3 & $(0)$ & 0.1 & $(-1)$ \\
\hline 14 & 1 & $(-1)$ & 0.3 & $(0)$ & 29 & 3 & $(0)$ & 0.5 & $(1)$ \\
\hline 15 & 1 & $(-1)$ & 0.5 & $(1)$ & & & & & \\
\hline
\end{tabular}

Table 4. Observed and predicted value for PU adhesive with PMDI.

\begin{tabular}{c|c|c|c|c|c|c|c} 
Run & $\begin{array}{c}\text { Gel Time (min) } \\
\text { Observed } \\
\text { value }\end{array}$ & $\begin{array}{c}\text { Gel Time } \\
\text { (min) } \\
\text { Predicted } \\
\text { value }\end{array}$ & $\begin{array}{c}\text { Lap shear } \\
\text { strength } \\
\text { (Mpa) }\end{array}$ & Run & $\begin{array}{c}\text { Gel Time } \\
\text { (min) } \\
\text { Observed } \\
\text { value }\end{array}$ & $\begin{array}{c}\text { Gel Time } \\
\text { (min) } \\
\text { Predicted } \\
\text { value }\end{array}$ & $\begin{array}{c}\text { Lap shear } \\
\text { strength } \\
\text { (Mpa) }\end{array}$ \\
\hline 1 & 37 & 35.90 & 0.734 & 16 & 34 & 35.90 & 1.215 \\
\hline 2 & 59 & 53.12 & 1.001 & 17 & 28 & 25.67 & 0.792 \\
\hline 3 & 22 & 23.31 & 0.76 & 18 & 48 & 46.12 & 1.056 \\
\hline 4 & 66 & 68.92 & 1.389 & 19 & 10 & 14.04 & 0.832 \\
\hline 5 & 35 & 35.90 & 1.36 & 20 & 37 & 37.31 & 1.017 \\
\hline 6 & 38 & 46.12 & 0.795 & 21 & 28 & 25.67 & 0.792 \\
\hline 7 & 73 & 68.92 & 1.013 & 22 & 40 & 35.90 & 0.984 \\
\hline 8 & 45 & 46.12 & 0.987 & 23 & 19 & 18.67 & 1.371 \\
\hline 9 & 12 & 14.04 & 0.791 & 24 & 51 & 53.12 & 0.983 \\
\hline 10 & 68 & 68.92 & 0.937 & 25 & 36 & 35.90 & 1.086 \\
\hline 11 & 34 & 37.31 & 0.896 & 26 & 20 & 25.67 & 1.527 \\
\hline 12 & 24 & 23.31 & 1.059 & 27 & 21 & 23.31 & 0.754 \\
\hline 13 & 14 & 14.04 & 0.737 & 28 & 55 & 53.12 & 0.955 \\
\hline 14 & 38 & 37.31 & 0.965 & 29 & 25 & 18.67 & 0.949 \\
\hline 15 & 24 & 18.67 & 0.823 & & & &
\end{tabular}

According to results, it can be concluded that with increasing catalyst and glycerol values to adhesive compound, gel time was decreased. [39,40]. Lap shear strength with increasing catalyst and glycerol values first increased and then decreased. The statistical significance of the 2F1 model was measured by the (ANOVA) as reported in Table 5. The Model F-value of 202.29 implies that the model is significant. Values of "Prob > F" less than 0.0500 indicate model terms are significant. $\mathrm{AB}$ are significant model terms in this case, where $A$ is catalyst and B is glycerol. By determination of coefficient $\left(R^{2}\right)$ it can be determined the fit of the model. Also, according to the value of the determination coefficient $\left(R^{2}=0.9604\right)$ can be said that $3.96 \%$ of the total variable by the model was not described. For the model to be stronger and a better prediction, the $\mathrm{R}^{2}$ should be closer to 1 . The amount of adjusted $\mathrm{R}^{2}=0.9557$ is also high that which shows the high significance of the model. Also, if the predicted $\mathrm{R}^{2}$ is high, it shows a high significance of the model. The predicted $\mathrm{R}^{2}$ obtained 0.9487 , showing that the model $5.13 \%$ of the total variations does not describe. This also showed that the predicted $\mathrm{R}^{2}$ of 0.9487 with the adjusted $\mathrm{R}^{2}$ of 0.9557 is in reasonable agreement. Meanwhile, 
a relatively low amount of the coefficient of variation $(\mathrm{CV}=9.85)$ shows acceptable accuracy and reliability of the experiments $[46,47]$.

Table 5.Analysis of variance (ANOVA) for the response surface 2F1model.

\begin{tabular}{|c|c|c|c|c|c|}
\hline Source & SS & DF & MS & $\mathbf{F}$ & Probability \\
\hline Model & 7593.86 & 3 & 2531.29 & 202.29 & $<0.0001$ significant \\
\hline A-C* & 5338.89 & 1 & & 426.66 & $<0.0001$ \\
\hline B-G** & 1880.89 & 1 & 1880.89 & 150.31 & $<0.0001$ \\
\hline $\mathbf{A B}$ & 374.08 & 1 & 374.08 & 29.90 & $<0.0001$ \\
\hline Residual & 312.83 & 25 & 12.51 & & \\
\hline Lack of Fit & 96.30 & 5 & 19.26 & 1.78 & $\begin{array}{l}0.1631 \mathrm{not} \\
\text { significant }\end{array}$ \\
\hline Lack of Fit & 96.30 & 5 & 19.26 & 1.78 & $\begin{array}{l}0.1631 \text { not } \\
\text { significant }\end{array}$ \\
\hline Pure Error & 216.53 & 20 & 10.83 & & \\
\hline Cor Total & 7906.69 & 28 & & & \\
\hline
\end{tabular}

The "Lack of Fit F-value" of 1.78 implies the Lack of Fit is not significant relative to the pure error. There is a $16.31 \%$ chance that a "Lack of Fit F-value" this large could occur due to noise. Non-significant lack of fit is good.

The regression model for gel time (PU PMDI) in coded factor is expressed by the following equation (7):

Gel time $(\min )=+35.90-17.22 \mathrm{~A}-10.22 \mathrm{~B}+5.58 \mathrm{~A} \mathrm{~B}$

This equation indicates the effects of two parameters, catalyst and glycerol, on adhesive gel time. Also, it shows that these parameters have more significant effects on the gel time.

Figure 2 shows the effects of catalyst and glycerol on gel time. Minimum and maximum the value of the gel time obtained in Figure almost 14.0354 and 68.9243, respectively. It is obvious that with increasing catalyst and glycerol values, gel time decreases. According to Figure 2, it can be found that gel time is very sensitive to increased catalyst and glycerol values.

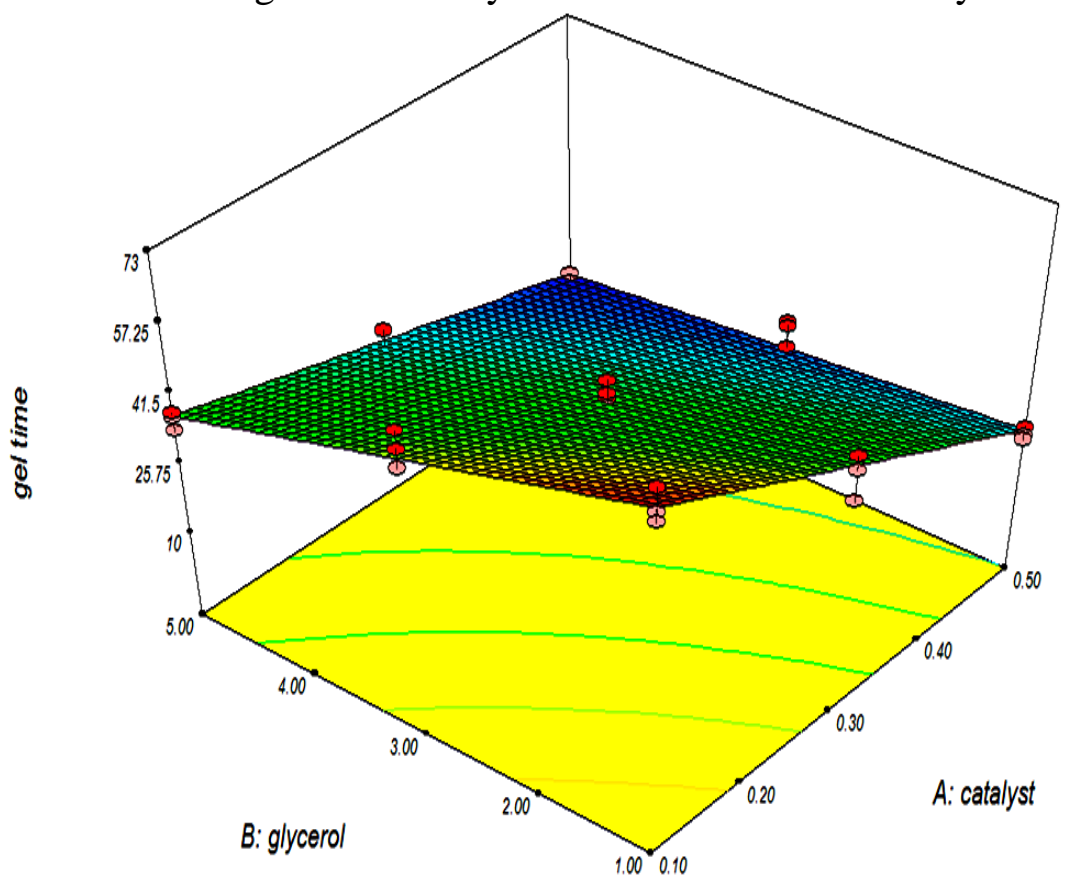

Figure 2. Response surface plot for the effects of A: catalyst and B: glycerol on gel time for PU adhesive to PMDI. 
3.2.2. Polyurethane adhesive with TDI.

The real value and the coded value obtained from the experimental design shown in Table 6. The results observed value and predicted value of the gel time are shown in Table 7. The statistical significance of the quadratic model was measured by ANOVA, as presented in Table 8.

Table 6. Real value and a coded value obtained from (CCD) experimental design (PU TDI).

\begin{tabular}{c|c|c|c|c|c|c|c|c|c} 
Run & \multicolumn{2}{|c|}{ Glycerol (\%) } & \multicolumn{2}{c|}{ Catalyst $(\boldsymbol{\%})$} & \multicolumn{2}{c|}{ Run } & \multicolumn{2}{c|}{ Glycerol (\%) } & \multicolumn{2}{c}{ Catalyst (\%) } \\
\hline 1 & 1 & $(-1)^{*}$ & 0.5 & $(1)^{*}$ & 16 & 3 & $(0)^{*}$ & 0.3 & $(0)^{*}$ \\
\hline 2 & 3 & $(0)$ & 0.5 & $(1)$ & 17 & 1 & $(-1)$ & 0.5 & $(1)$ \\
\hline 3 & 5 & $(1)$ & 0.3 & $(0)$ & 18 & 3 & $(0)$ & 0.3 & $(0)$ \\
\hline 4 & 1 & $(-1)$ & 0.1 & $(-1)$ & 19 & 5 & $(1)$ & 0.3 & $(0)$ \\
\hline 5 & 3 & $(0)$ & 0.1 & $(-1)$ & 20 & 1 & $(-1)$ & 0.3 & $(0)$ \\
\hline 6 & 3 & $(0)$ & 0.5 & $(1)$ & 21 & 1 & $(-1)$ & 0.3 & $(0)$ \\
\hline 7 & 5 & $(1)$ & 0.5 & $(1)$ & 22 & 1 & $(-1)$ & 0.5 & $(1)$ \\
\hline 8 & 3 & $(0)$ & 0.1 & $(-1)$ & 23 & 5 & $(1)$ & 0.1 & $(-1)$ \\
\hline 9 & 3 & $(0)$ & 0.3 & $(0)$ & 24 & 3 & $(0)$ & 0.5 & $(1)$ \\
\hline 10 & 3 & $(0)$ & 0.3 & $(0)$ & 25 & 1 & $(-1)$ & 0.3 & $(0)$ \\
\hline 11 & 1 & $(-1)$ & 0.1 & $(-1)$ & 26 & 1 & $(-1)$ & 0.1 & $(-1)$ \\
\hline 12 & 5 & $(1)$ & 0.3 & $(0)$ & 27 & 5 & $(1)$ & 0.1 & $(-1)$ \\
\hline 13 & 5 & $(1)$ & 0.5 & $(1)$ & 28 & 5 & $(1)$ & 0.1 & $(-1)$ \\
\hline 14 & 3 & $(0)$ & 0.3 & $(0)$ & 29 & 5 & $(1)$ & 0.5 & $(1)$ \\
\hline 15 & 3 & $(0)$ & 0.1 & $(-1)$ & & & & & \\
\hline & & & & & & & Coded value ()$^{*}$
\end{tabular}

Also, Table 7 shows the results of gel time and lap shear strength after adding catalyst and glycerol to the adhesive compound. According to results, with increasing catalyst and glycerol values to adhesive compound, gel time decreased [39,40]. Lap shear strength with increasing glycerol value first increased, but when catalyst value increased, this strength decreased.

Table 7. The observed and predicted value for PU adhesive with TDI.

\begin{tabular}{c|c|c|c|c|c|c|c} 
Run & $\begin{array}{c}\text { Gel Time (min) } \\
\text { Observed } \\
\text { value }\end{array}$ & $\begin{array}{c}\text { Gel Time } \\
\text { (min) } \\
\text { Predicted } \\
\text { value }\end{array}$ & $\begin{array}{c}\text { Lap shear } \\
\text { strength } \\
\text { (Mpa) }\end{array}$ & Run & $\begin{array}{c}\text { Gel Time } \\
\text { (min) } \\
\text { Observed } \\
\text { value }\end{array}$ & $\begin{array}{c}\text { Gel Time } \\
\text { (min) } \\
\text { Predicted } \\
\text { value }\end{array}$ & $\begin{array}{c}\text { Lap shear } \\
\text { strength } \\
\text { (Mpa) }\end{array}$ \\
\hline 1 & 35 & 33.50 & 1.067 & 16 & 64 & 65 & 1.102 \\
\hline 2 & 30 & 33.68 & 1.461 & 17 & 33 & 33.50 & 0.768 \\
\hline 3 & 35 & 33.50 & 1.035 & 18 & 63 & 65 & 1.37 \\
\hline 4 & 130 & 124.90 & 0.743 & 19 & 37 & 38.17 & 1.097 \\
\hline 5 & 95 & 98 & 0.901 & 20 & 75 & 77.50 & 1.295 \\
\hline 6 & 35 & 38.17 & 1.098 & 21 & 78 & 77.50 & 1.367 \\
\hline 7 & 20 & 19.50 & 1.173 & 22 & 35 & 33.68 & 0.793 \\
\hline 8 & 98 & 98 & 0.856 & 23 & 90 & 98 & 0.826 \\
\hline 9 & 73 & 65 & 1.45 & 24 & 31 & 33.68 & 1.308 \\
\hline 10 & 68 & 65 & 1.097 & 25 & 77 & 77.50 & 1.1002 \\
\hline 11 & 127 & 124.90 & 0.867 & 26 & 125 & 124.90 & 0.705 \\
\hline 12 & 40 & 38.17 & 1.38 & 27 & 85 & 77.50 & 0.77 \\
\hline 13 & 19 & 18.46 & 1.071 & 28 & 81 & 77.50 & 0.827 \\
\hline 14 & 62 & 65 & 1.68 & 29 & 22 & 19.50 & 0.803 \\
\hline 15 & 101 & 98 & 0.84 & & & &
\end{tabular}

The Model F-value of 315.60 implies the model is significant. Values of "Prob > F" less than 0.0500 indicate model terms are significant. In this case, A (catalyst), B (glycerol), $\mathrm{AB}$ are significant model terms. Also, according to the value of the determination coefficient 
$\left(\mathrm{R}^{2}=0.9893\right)$ can be said that $1.07 \%$ of the total variable by the model was not described. The closer the $\mathrm{R}^{2}$ is to 1 , the stronger the model and the better it predicts the response. For the model to be stronger and a better prediction, the $\mathrm{R}^{2}$ should be closer to 1 . The amount of adjusted $\mathrm{R}^{2}=0.9862$ is also high that which shows the high significance of the model. Also, if the predicted $\mathrm{R}^{2}$ is high, it shows a high significance of the model. The predicted $\mathrm{R}^{2}$ obtained 0.9824 , showing that the model $1.76 \%$ of the total variations does not describe. This also showed that the predicted $\mathrm{R}^{2}$ of 0.9824 with the adjusted $\mathrm{R}^{2}$ of 0.9862 is in reasonable agreement. Meanwhile, a relatively low amount of the coefficient of variation $(\mathrm{CV}=5.76)$ shows acceptable accuracy and reliability of the experiments $[43,46]$.

The "Lack of Fit F-value" of 2.50 implies the Lack of Fit is not significant relative to the pure error. There is a $13.34 \%$ chance that a "Lack of Fit F-value" this large could occur due to noise. Non-significant lack of fit is good.

The regression model for gel time (PU TDI) in coded factor is expressed by the following equation (8):

Gel time $(\min )=+65.00-32.17 \mathrm{~A}-19.67 \mathrm{~B}+12.67 \mathrm{~A} \mathrm{~B}+0.83 \mathrm{~A}^{2}-7.17 \mathrm{~B}^{2}$

This equation indicates the effects of two parameters, catalyst and glycerol, on adhesive gel time. Also, it shows that these parameters have more significant effects on the gel time.

Table 8. Analysis of variance (ANOVA) for the response surface Quadratic model.

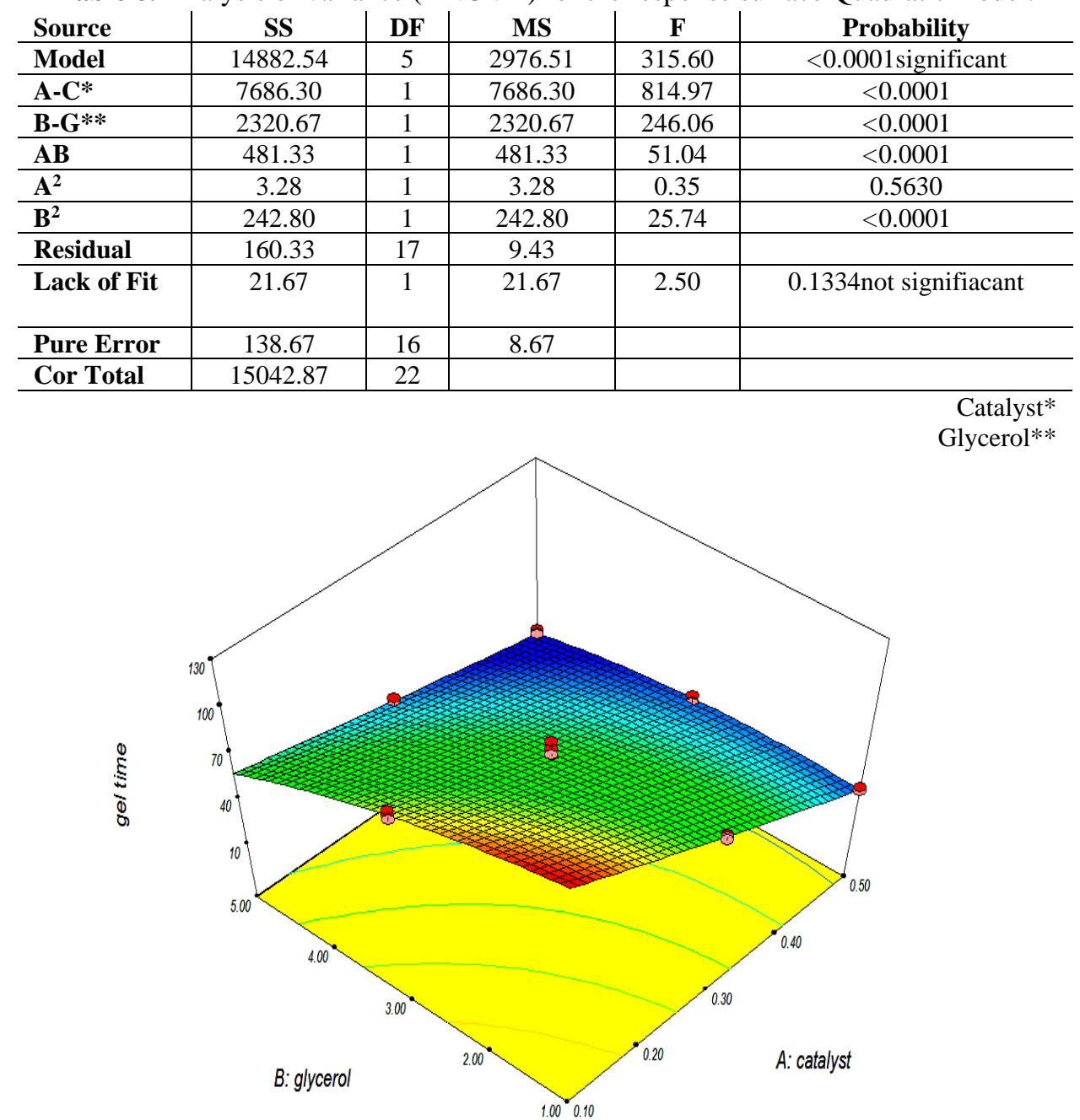

Figure 3. Response surface plot for the effects of A: catalyst and B: glycerol on gel time for PU adhesive to TDI. 
Figure 3 shows the effects of catalyst and glycerol on gel time. Minimum and maximum the value of the gel time obtained in Figure almost 19.5 and 123.167, respectively. It is obvious that with increasing catalyst and glycerol values, gel time decreases.

\subsubsection{Optimization using the desirability functional.}

For the optimization, we select the desired target from the menu for each factor and response. The possible goals are: maximize, minimize, and target, within range, none. A maximum and a minimum level for each parameter contained should be provided. The aims are joined into an entire desirability function. Desirability as target function ranges from zero beyond the limits to one at the aim. Figure 4 shows ramp desirability for polyurethane adhesives PMDI and TDI that it was obtained from optimum points. A maximum level of gel time (73 min) and lap shear strength $(1.527 \mathrm{Mpa})$ and catalyst within the range of $0.1-0.5 \%$ and glycerol within a range of $1-5 \%$ were set for maximum desirability polyurethane adhesive with PMDI. The best local maximums were found to be at gel time of $63.51 \mathrm{~min}$ and lap shear strength of $1.084 \mathrm{Mpa}$ and catalyst $0.11 \%$, and glycerol $1.56 \%$. The desirability $(0.612)$ shows that the accounted function may display the desired situation and experimental model. A maximum level of lap shear strength (1.527 Mpa) and gel time within the range of 35-90 min and catalyst within range of $0.1-0.5 \%$ and glycerol within range of $1-5 \%$ wa set for maximum desirability for polyurethane adhesive with TDI. The best local maximums were found to be at gel time (57.58 $\mathrm{min})$ and lap shear strength $(1.379 \mathrm{Mpa})$ and catalyst $0.34 \%$, and glycerol $3.121 \%$. The desirability (0.691) shows that the accounted function may display the desired situation and experimental model.
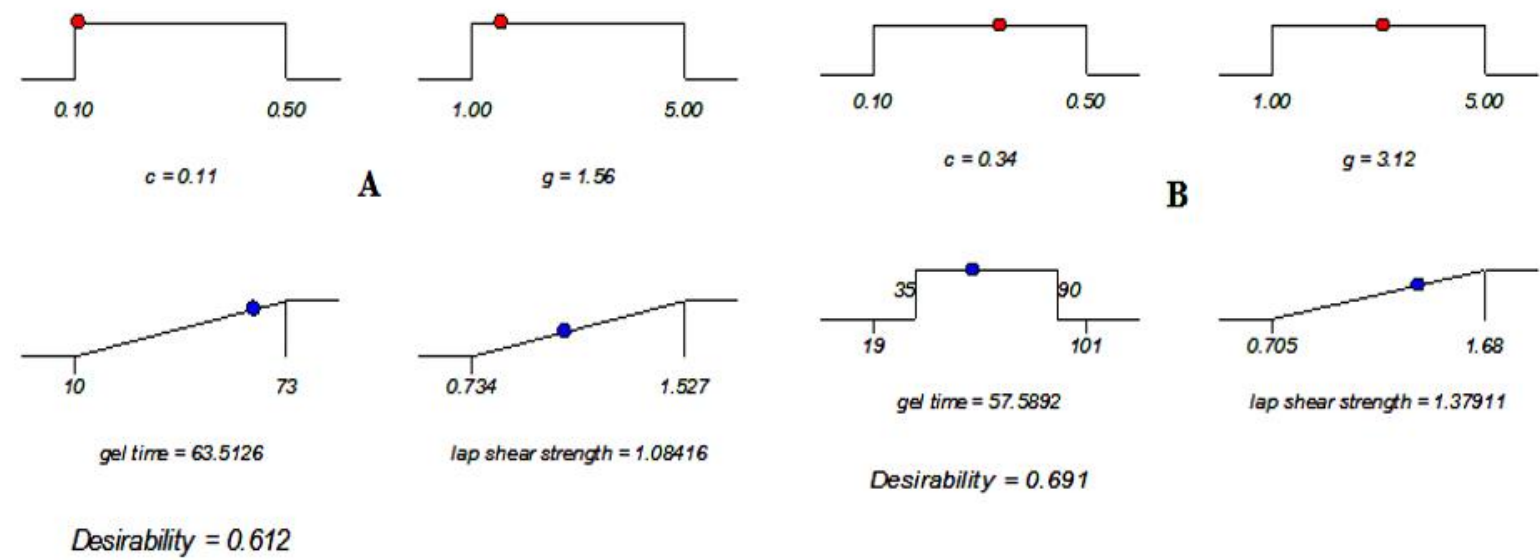

A
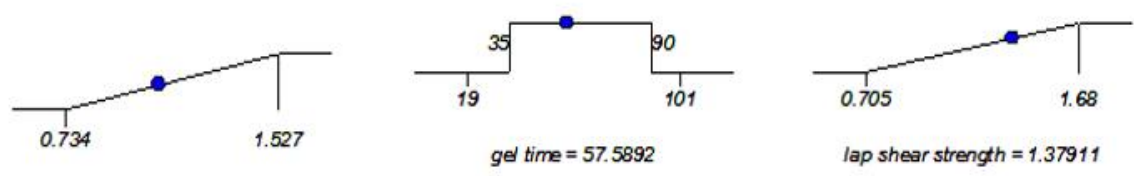

lap shear strength $=1.08416$

Desirability $=0.691$

Figure 4. Desirability ramp for numerical optimization: the catalyst and glycerol, gel time and lap shear strength. A: PU (PMDI) and B: PU (TDI).

\section{Conclusions}

FTIR results revealed the existence of the hydroxyl groups $(\mathrm{OH})$ in the liquefied Beech sawdust and confirmed that the liquefied wood sawdust with temperature $130^{\circ} \mathrm{C}$ and $120 \mathrm{~min}$ is a source of polyols and a potential chemical stock for the synthesis of polyurethane.

The result shows that DBTL as catalyst and glycerol as cross-linker has more effects on gel time. The result of optimization by RSM showed that catalyst $0.11 \%$, glycerol $1.56 \%$, gel time $63.51 \mathrm{~min}$ and lap shear strength $1.084 \mathrm{Mpa}$ for PU adhesive with PMDI and catalyst 0.34, glycerol 3.12\%, gel time $57.58 \mathrm{~min}$ and lap shear strength $1.37 \mathrm{Mpa}$ for PU adhesive with TDI were appropriate. 


\section{Funding}

This research received no external funding.

\section{Acknowledgments}

\section{The authors are grateful for the support of the Wood and Paper Science and Technology Department, Faculty of Natural Resources, Tarbiat Modares University, Noor, Iran.}

\section{Conflicts of Interest}

The authors declare no conflict of interest.

\section{References}

1. Wang, Q.; Tuohedi, N. Polyurethane Foams and Bio-Polyols from Liquefied Cotton Stalk AgriculturalWaste. SUSTDE 2020, 12, 4214, Https://doi.org/10.3390/su12104214.

2. Zhang, Q.; Chen, W.; Qu, G.; Lin, X.; Han, D.; Yan, X.; Zhang, H. Liquefaction of Peanut Shells with Cation Exchange Resin and Sulfuric Acid as Dual Catalyst for the Subsequent Synthesis of Rigid Polyurethane Foam. Polymers 2019, 11, 993, Https://doi.org/ 10.3390/polym11060993 .

3. McDonald, R.I.; Mansur, A.V.; Ascensão, F. Research gaps in knowledge of the impact of urban growth on biodiversity. Nat. Sustain. 2020, 3,16-24, Https://doi.org/10.1038/s41893-019-0436-6.

4. Gama, N.; Ferreira, A.; Barros-Timmons, A. Cure and performance of castor oil polyurethane adhesive. Int J Adhes Adhe 2019,95, 102413, Https://doi.org/ 10.1016/j.ijadhadh.2019.102413.

5. Jingmiao, Z.; Hori, N.; Takemura, A. Optimization of agricultural wastes liquefaction process and preparing bio- based polyurethane foams by the obtained polyols. Ind. Crop. Prod 2019, 138, 111455, Https://doi.org/10.1016/j.indcrop.2019.06.018.

6. Jung, J.Y.; Yu, J.; Lee, E.Y. Completely Bio-based Polyol Production from Sunflower Stalk Saccharification Lignin Residue via Solvothermal Liquefaction Using Biobutanediol Solvent and Application to Biopolyurethane Synthesis. J Polym Environ 2018, 26, 3493-3501, Https://doi.org/ 10.1007/s10924-018-1235-2.

7. Li, H.; Xu, C.; Yuan, Z.; Wei, Q. Synthesis of bio-based polyurethane foams with liquefied wheat straw: $\begin{array}{lllll}\text { process optimization. BIOMASS BIOENERG } & \mathbf{2 0 1 8}, \quad 111,134\end{array}$ 140, https://doi.org/10.1016/j.biombioe.2018.02.011.

8. Meng, F.; Zhang, X.; Yu, W.; Zhang, Y. Kinetic analysis of cellulose extraction from banana pseudostem by liquefaction in polyhydric alcohols. Ind. Crop. Prod 2019, 137, 377-385, Https://doi.org/ 10.1016/j.indcrop.2019.05.025.

9. Addis, C.C.; Koh, R. S.; Gordon, M. B. Preparation and Characterization of a Bio-based Polymeric Wood Adhesive Derived from Linseed Oil. Int $J$ Adhes Adhe 2020, 102, https://doi.org/10.1016/j.ijadhadh.2020.102655.

10. Amran, U.A.; Zakaria, S.; Chia, C.H. Polyols and rigid polyurethane foams derived from liquefied lignocellulosic and cellulosic biomass. Cellulose 2019, 26,3231-3246,https://doi.org/10.1007/s10570019-02271-w.

11. Tenorio-Alfonso, A.; Carmen Sánchez, M.; Franco, J.M. A Review of the Sustainable Approaches in the Production of Bio-based Polyurethanes and Their Applications in the Adhesive Field. J Polym Environ 2020, 28, 749-774, Https:// doi.org/10.1007/s10924-020-01659-1.

12. Serrano, L.; Rincón, E.; García, A.; Rodríguez, J.; Briones, R. Bio-Degradable Polyurethane Foams Produced by Liquefied Polyol from Wheat Straw Biomass. Polym 2020, 12, 2646, Https://doi.org/10.3390/polym12112646.

13. Zhang, H.R.; Ding, F.; Luo, C.R.; Xiong, L.; Chen, X.D. Liquefaction and characterization of acid hydrolysis residue of corncob in polyhydric alcohols. J Industrial Crop and Pro 2012, 39, 47-51, Https:// doi.org/10.1016/j.indcrop.2012.02.010.

14. Zhang, Y.; Liu, Z.; Liu, H.; Hui, L.; Wang, H.; Liu, H. Characterization of liquefied products from corn stalk and its biomass components by polyhydric alcohols with phosphoric acid. Carbohydr Polym 2019, 215, 170-178, Https://doi.org/ 10.1016/j.carbpol.2019.03.096.

15. Rincón, E.; Balu, A.M.; Luque, R.; Serrano, L. Insulating rigid polyurethane foams from laurel tree pruning based polyol. J. Appl. Polym. Sci. 2020, 138, 49789, https://doi.org/10.1002/app.49789.

16. Chen, H.Z.; Zhang, Y.Z.; Xie, S.P. Selective liquefaction of wheat straw in phenol and its fractionation. J Appl Biochem and Biotech 2012, 167, 250-258, Https://doi.org/ 10.1007/s12010-012-9675-y.

17. Vargas-Gutiérrez, C.V.; Castro-Salazar, H.T.; Ríos-Reyes, C.A. Synthesis and properties of polyurethane foams obtained from cassava starch and rice by-products. J. Mex. Chem. Soc. 2018, 62, 1- 
8, https://doi.org/10.29356/jmcs.v62i3.778.

18. Yeoh, F.H.; Lee, C.S.; Kang, Y.B.; Wong, S.F.; Cheng, S.F.; Ng, W.S. Production of Biodegradable Palm Oil-Based Polyurethane as Potential Biomaterial for Biomedical Applications. Polymers. 2020, 12,1842. Https://doi.org/10.3390/polym12081842.

19. Chen, W.; Zhang, Q.; Lin, X.; Jiang, K.; Han, D. The Degradation and Repolymerization Analysis on Solvolysis Liquefaction of Corn Stalk. Polymers 2020, 2337. https://doi.org/10.3390/polym12102337.

20. Gadhave, R. V.; Mahanwar, P. A.; Gadekar, P.T. Bio-renewable sources for synthesis of eco-friendly polyurethane adhesives. Open J. Polym. Chem 2017, 7, 57-75, Https://doi.org/10.4236/ojpchem.2017.74005.

21. Juhaida, M.F.; Paridah, M.T.; Hilmi, M.M.; Sarani, Z.; Jalaluddin, H.; MohamadZaki, A.R. Liquefaction of kenaf (Hibiscus cannabinus L.) core for wood laminating adhesive. Biores Technol 2010, 101, 13551360, Https://doi.org/10.1016/j.biortech.2009.09.048.

22. Gosz, K.; Kowalkowska-Zedler, D.; Haponiuk, J.; Piszczyk, L. Liquefaction of alder wood as the source of renewable and sustainable polyols for preparation of polyurethane resins. Wood Sci. Technol 2020, 54, 103-121, Https://doi.org/10.1007/s00226-019-01152-6.

23. Huang, H.; Chang, Y.; Lai, F.; Zhou, C.; Pan, Z.; Xiao, X.; Wang, J.; Zhou, C. Co-liquefaction of sewage sludge and rice straw/wood sawdust: The effect of process parameters on the yields/properties of bio-oil and biochar products. Energy 2019, 173, 140-150, Https://doi.org/ 10.1016/j.energy.2019.02.071.

24. Zhang, J.; Hori, N.; Takemura, A. Influence of NCO/OH ratio on preparation of four agricultural wastes liquefied polyols based polyurethane foams. Polym. Degrad. Stab. 2020, 179, 109256, Https://doi.org/10.1016/j.polymdegradstab.2020.109256.

25. Fernandes, F.; Matos, S.; Gaspar, D.; Silva, L.; Paulo, I.; Vieira, S.; C. R. Pinto, P.; Bordado, J.; Galhano dos Santos, R. Boosting the Higher Heating Value of Eucalyptus globules via Thermochemical Liquefaction. Sustain 2021, 13, 3717, Https://doi.org/10.3390/su13073717.

26. Desai, S.; Emanuel, A.; Sinha, V. Biomaterial based polyurethane adhesive for bonding rubber and wood joints. J Polym Res 2003, 10, 275-281, Https://doi.org/ 10.1023/ B:JPOL.0000004630.77120.bb.

27. Kong, X.; Liu, G.; Curtis, G. M. Characterization of canola oil based polyurethane wood adhesives. Inter J Adhes Adhes 2011, 31, 559-564, Https://doi.org/10.1016/j.ijadhadh.2011.05.004.

28. Yagci, Y.E. Synthesis of Polyols for the preparation of biodegradable polyurethanes. Masters thesis 2004, Durham University.

29. Zhang, H.; Luo, J.; Li,Y.; Guo, H.; Xiong, L.; Chen, X. Acid-Catalyzed Liquefaction of Bagasse in the Presence of Polyhydric Alcohol. J Appl Biochem and Biotech 2013, 170, 1780-1791, Https:// doi.org/10.1007/s12010-013-0300-5.

30. Gollakota, A.; Savage, P.E. Fast and Isothermal Hydrothermal Liquefaction of Polysaccharide $\begin{array}{llllll}\text { Feedstocks. } & \text { ACS Sustain. } \quad \text { Chem. }\end{array}$ Https://doi.org/10.1021/acssuschemeng.9b06873.

31. Lligadas, G. ; Ronda, J.C.; Galià, M. ; Cádiz, V. Poly(ether urethane) networks from renewable resources as candidate biomaterials: synthesis and characterization. Biomacromolecules 2007, 8, 686692, Https:// doi.org/10.1021/bm060977h.

32. Venkatachalam, C.D.; Ravichandran, S.R.; Sengottian, M. Lignocellulosic and algal biomass for biocrude production using hydrothermal liquefaction: Conversion techniques, mechanism and process conditions: A review. Environ. Eng. Res. 2020, 27, 200555, Https://doi.org/10.4491/eer.2020.555.

33. Yamada, T.; Ono, H. Rapid liquefaction of lignocellulosic waste by using ethylene carbonate. Biores Technol 1999, 70, 61-67, Https://doi.org/10.1016/S0960-8524(99)00008-5.

34. Pizzi, A.; Mittal, K.L. Wood adhesives, Leiden, the Netherlands: Brill Academic Publishers 2010, Https:// doi.org/10.1080/10426914.2012.689463.

35. Desai, S.; Patel, J.V.; Sinha, V. Polyurethane adhesive system from biomaterial-based polyol for bonding wood. Int J Adhes Adhes 2003, 23, 393-399, Https://doi.org/10.1016/S0143-7496(03)00070-8.

36. Somani, K.P.; Kansara, S.S.; Patel, N. K.; Rakshit, A. K. Castor oil based polyurethane adhesives for wood-to-wood bonding. Int $J$ Adhes Adhes 2003, 23, 269-275, Https://doi.org/ 10.1016/S01437496(03)00044-7.

37. Meyers, G.E. How mole ratio of UF resin affects formaldehyde emission and other properties: a literature critique. For Prod J 1984, 34, 35-41.

38. Phetphaisit, C.W.; Bumee, R.; Namahoot, J.; Ruamcharoen, J.; Ruamcharoen, P. Polyurethane polyester elastomer: innovative environmental friendly wood adhesive from modified PETs and hydroxyl liquid natural rubber polyols. Int $J$ Adhes Adhe 2013, 41, 127-131, Https:// doi.org/10.1016/j.ijadhadh.2012.11.007.

39. Daneshvar, S.; Behrooz, R.; Kazemi Najafi, S.; Mir Mohamad Sadeghi, G. Characterization of polyurethane wood adhesive prepared from liquefied sawdust by ethylene carbonate. Bioresources 2019, 14, 796-815,Https://doi.org/10.15376/biores.14.1.796-815.

40. Khoon Poh, A.; Choy Sin, L.; Sit Foon, C.; Cheng Hock, C. Polyurethane wood adhesive from palm oil- 
based polyester polyol. Adhes Sci and Technol 2014, 28, 1020-1033, Https://doi.org/10.1080/01694243.2014.883772.

41. Choi, S.W.; Seo, D.W.; Lim, Y.D.; Jeong, Y.G.; Islam Mollah, M.S.; Park, H.; Hong, T.W.; Kim, W.G. Synthesis and properties of multi hydroxy soybean oil from soybean oil and polymericmethylenediphenyl-4,4'-diisocyanate/multi hydroxy soybean oil polyurethane adhesive to wood. J Appl Polym Sci 2011, 121, 764-769, Https://doi.org/ 10.1002/app.33405.

42. Mishra, D. Eco-economical polyurethane wood adhesives from cellulosic waste: synthesis, characterization and adhesion study. Int $J$ Adhes Adhes 2010, 30, 47-54, Https://doi.org/10.1016/j.ijadhadh.2009.08.003.

43. Myers, H.R.; Montgomery, D.C. Response Surface Methodology: Process and Product optimization Using Design Experiment. John Wiley \& Sons 1995, New York.

44. Bayraktar, E. Response surface optimization of the separation of DL-tryptophan using on emulsion liquid membrane. Process Biochem 2000, 37, 169-175, Https://doi.org/ 10.1016/S0032-9592(01)00192-3.

45. Box, G.E.P.; Draper, N.R. Empirical Model-building and Response Surfaces. John Wiley\&Sons, 1987, New York.

46. Khuri, AI.; Cornell, J.A. Response surface: Design and Analyses. 2nd ed., Marcel Dekker, 1996, New York.

47. Kuehl, R.O. Design of Experiment: Statistical Principles of Research Design and analysis, 2nd ed., Duxbury press, Pacific Grove, CA 2000, 20-25.

48. Montgomery, D.C. Design and analysis of experiment. John Wiley and Sons 2005, New York.

49. Hu, S.; Luo, X.; Li, Y. Polyols and polyurethanes from the liquefaction of lignocellulosic biomass.Department of Food. Agricultural and Biological Engineering, Chem Sus Chem 2014, 7, 66-72, Https:// doi.org/10.1002/cssc.201300760.

50. Bodirlau, R.; Teaca, C.A. Fourier transforms infra-red spectroscopy and thermal analysis of lignocellulose fillers treated with organic anhydrides. Rom Journ Phys 2009, 54, 93-104.

51. Meilan, A. C.; Goodman, A.; Baron, M.; Rodriguez, J. G. An specific case in the classification of woods by FTIR and chemo metrics: Discrimination of Fagales from Malpighiales. J Cellulose 2014, 21, 261273, Https://doi.org/10.1007/s10570-013-0093-2.

52. Salim, R.M.; Asik, J.; Sarjadi, M.S. Chemical functional groups of extractives, cellulose and lignin extracted from native Leucaena leucocephala bark. Wood Sci.Technol, 2021, 55, 295-313, Https://doi.org/10.1007/s00226-020-01258-2.

53. Magalhães, S.; Filipe, A.; Melro, E.; Fernandes, C.; Vitorino, C.; Alves, L.; Anabela Romano, A.; Rasteiro, M.G.; Medronho, B. Lignin extraction from waste pine sawdust using a biomass derived binary solvent system. Polym 2021, 13, 1090, Https://doi.org/10.3390/polym13071090. 